\section{A microtome knife guard}

DAVID G. EVANS From the Department of Pathology, Dulwich Hospital, London

The base sledge microtome presents a hazard to the operator due to the length of blade that is exposed. Manipulation of the carriage requires hand movements close to the knife edge and serious lacerations may result.

A simple, effective guard has been devised, suitable for knives which have screw holes for handles at both ends. It consists of two perspex end-pieces (Fig. 1), attached to the knife ends by screws, and linked by a metal bar (Fig. 1b). The bar guards the whole length of the knife, with minimal interference to adjusting its position in the clamps. In addition the knife edge is protected from accidental damage should the tissue chuck be raised too high. When suitably aligned, the guard acts as a 'level finder' for the top of the tissue block.

Received for publication 25 March 1962.

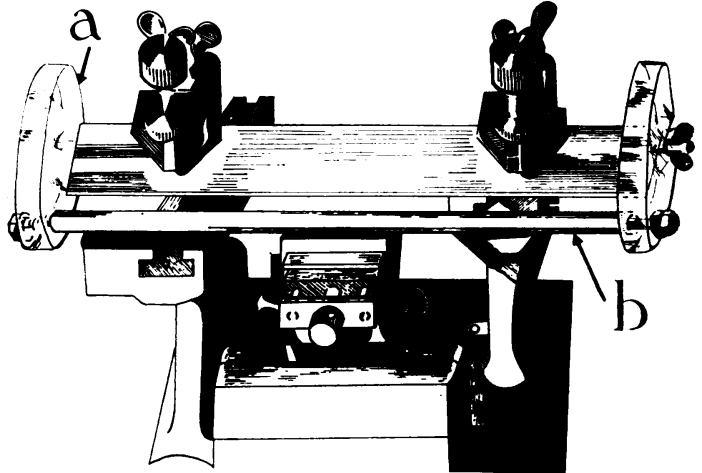

FIG. 1. Microtome knife guard in position.

The guard has been in daily use on an M.S.E. base sledge microtome for 10 months, and has proved satis-은 factory. It has allowed us to use this microtome to train student technicians without accident.

A modified version of this guard is obtainable from the patentees, Optical Instrument Services (Croydon) Ltd., 194A, Sydenham Road, Croydon, Surrey. 